\title{
Taiwanese Employees' Justice Perceptions of Co-Workers' Punitive Events
}

\author{
SHU-CHENG CHI \\ Department of Busines: Administration \\ National Taiwan University \\ HSIN-HSIN LO \\ Department of Busines: Administration \\ National Defense University, Taiwan
}

\begin{abstract}
The authors examined justice pirceptions of Taiwanese employees in response to co-workers' punitive events (punishment by a superior). They developed a hypothesis based on Chinese indigenous wu-lun principles and the concept of empathy. Results of the study showed that perceived vert cal (between superior and subordinate) and horizontal (between subordinates) relationships jointly affected justice perceptions. Respondents who perceived low (negative) leader-member exchange with the superior and high (positive) liking of the punished person showed the lowest justice perceptions. In conclusion, the authors note that comparative analysis of organizational justice is a promising direction for future research.
\end{abstract}

Key words: Chinese, leader-member exchange, organizational justice, punishment

PUNISHMENT has been defined as a superior's imposition of negative consequences or withdrawal of positive consequences for the purpose of decreasing the likelihood of a repetition of a subordinate's undesirable behaviors (Arvey \& Ivancevich, 1980). Unlike other management tools, the use of punishment has been the subject of wide debate and has often been labeled as morally inappropriate (Luthans \& Kreitner, 1985). It is because of this controversy that

This research was supported by a National Science Council in Taiwan grant (NSC 882416-H-002-025) to the first author. An earlier version of the article was presented in 2000 at The Second Asian Academy of Management Conference, Singapore. The authors would like to thank Julie Waxgiser for her assistance in completing this article for publication and Raymond Friedman and two anonymous reviewers for helpful comments on earlier drafts of this article.

Address correspondence to Shu-Cheng Chi, Department of Business Administration, National Taiwan University, No. 1, Sec. 4, Roosevelt Rd., Taipei, Taiwan; send e-mail to N136@mba.ntu.edu.tw. 
members of organizations are especially sensitive to punitive events and care greatly whether a punished co-worker receives the proper level of punishment in relation to his or her misconduct both in terms of severity and consistency (Atwater, Waldman, Carey, \& Cartier, 2001; Ball, Trevino, \& Sims, 1994; Trevino, 1992).

Our purpose in the present study was to investigate the following question: When a Taiwanese employee's co-worker is punished by a superior, are that employee's justice perceptions affected by his or her "elationship with the superior, by a relationship with the punished co-worker, or by both? Superior and coworker are two important relational categories for any particular employee because they are hierarchical positions at different levels. Yates and Lee (1996) proposed that Chinese organizational structure is strong vertically but weak horizontally. Chinese decision-making customs are highly sensitive to status differences (Hofstede, 1980). We expected to find that answers to the question would reflect a cultural tradition of Confucianism involving the five relationships of emperor-subject, father-son, husband-wife, elder-younger, and friend-friend (the wu-lun principles).

We focused our investigation on two particular categories of relationships within an organization: vertical relationships between superior and subordinate and horizontal relationships between two subordinates. We drew on literature in organizational behavior and used the concept of leader-member exchange to represent the former and interpersonal liking between the focal person and the punished co-worker to represent the latter. We contend that vertical and horizontal relationships may jointly affect a member's perceptions toward coworkers' punitive events.

Ordering relationships by status is a crucial element in Chinese societies. The wu-lun principles specify people's roles and behaviors in relation to one another and serve as a referent norm of social interactions. Furthermore, Chinese people use different justice rules depending on the nature of each interpersonal dyadic relationship (Leung \& Bond, 1984). They adopt equality rules for friends but equity rules for strangers. Hwang (2000, p. 168) stated,

Confucius advocated that procedural justice in social interaction should follow the principle of respecting the superior. ... In choosing an appropriate method for distributive justice, the resource allocator should follow the principle of favoring the intimate. Furthermore, from the Confucian perspective, it is righteous to make these decisions in this way.

Such ethical guidelines are dwelt on in the ancient Chinese wu-lun principles. We believe that such concepts have important implications for Chinese organizational members' perceptions and behavior. However, few researchers have shown the existence and impact of these concepts, either directly or indirectly, by examining Chinese employees' behaviors or perceptions as indicators of effects from different dyadic relationships. 


\section{Perspectives of Organizational Justice}

Organizational justice has received increased attention from scientists (Folger \& Cropanzano, 1998; Greenberg, 1996). Accumulated evidence supports the notion that a person's perception of organizational justice affects his or her job attitudes (Dailey \& Kirk, 1992; Konovsky \& Cropanzano, 1991; McFarlin \& Sweeney, 1992) and extra-role behaviors (Farh, Earley, \& Lin, 1997; Moorman, 1991; Moorman, Blakely, \& Niehoff, 1998).

In spite of pervasive support for the effects of organizational justice, theorists have disagreed on how people reach their justice judgments. Some hold a self-interest perspective and believe that organizational justice is instrumental for members' pursuit of self-interest. Others suggest that a person's moral conduct takes into account other people's well-being rather than operating simply on the basis of self-interest (Konovsky, 2000).

In relation to the former perspective, Konovsky (2000) identified two models of procedural justice: Thibaut and Walker's (1975) process control model and the social exchange model. Thibaut and Walker suggested that people prefer procedures that maximize their personal outcome and that procedural control is the best means for ensuring the best personal outcorne. Regarding the social exchange model, Konovsky stated, "Social exchange generates an expectation of some future return for contributions; ... social exchange relationships are based on individuals trusting that the other parties to the exchange will fairly discharge their obligations in the long run" (p. 493). In sum, people's main desire is to achieve favorable outcomes, and social exchange demands positive reciprocation and results in the stabilizing of relationships. People reach their justice judgments on the basis of self-interest and a fair amount of reciprocity of social exchange.

Lind and Tyler and associates (Blader \& Tyler, 2000; Lind, Kray, \& Thompson, 1998; Lind \& Tyler, 1988; Tyler \& Lind, 1992) proposed a "group-value model"; they argued that group members are concerned with authority structure and care for long-term relationships with their superiors and with other co-workers. Justice is thus evaluated in relational terms. People use criteria that provide them with cues regarding their relationship with the group. Moreover, Lind and Earley (1992) proposed that such group-oriented processes are more readily stimulated in collectivistic cultures than in individualistic ones. There seems to be a need for non-Western evidence on a relational model of organizational justice. We attempted to serve this purpose with his study.

\section{Perceiving Punitive Events Empathetically by Taiwanese Employees}

Farh et al. (1997) found that traditional Chinese values play a crucial role in determining Taiwanese employees' justice perceptions. We hypothesized that Taiwanese employees' justice perceptions toward co-workers' punitive events would be strongly related to their particular dyadic relationships with the superior and 
with the punished co-worker. One major reason that such relationships have an impact on justice perceptions lies in the person's empathy with a target person (cf. Davidson \& Friedman, 1998). As Batson (1991) stated, empathy "is a result of the perceiver adopting the perspective of the person in need" (p. 83). To empathize, someone "imagin(es) how the person is affected by his or her situation" (p. 84). The higher a person's attachment to the target, the stronger the empathy.

We expected that Taiwanese employees' justice perceptions toward coworkers' punitive events would be related to their empathy toward the punished co-worker or toward the superior. On the basis of the prediction of Chinese wulun principles, third-party employees are likely to show a higher degree of empathy toward a superior while putting blame on the punished, other things being equal. This prediction is opposed to that normally found in Western culture, in which there is often a general distrust of people in higher ranks.

\section{Approximates of Vertical and Horizontal Relationships}

We used leader-member exchange to assess subordinates' judgment of superior-subordinate relationships. Graen and Scandura (1987) argued that a superior tends to treat each subordinate differently. The differences in a dyadic exchange are shown in the supervisor's expression of trust in and delegation to the subordinate and of the subordinate's loyalty to, commitment to, and trust in the superior (Yukl, 2000). Subordinates are likely to confirm superiors' behaviors toward them by responding to expectations as self-fulfilling prophecies (Darley \& Fazio, 1980).

The leader-member exchange between superior and subordinate may affect a member's justice perceptions as follows: A subordinate who perceives a high (or positive) leader-member exchange with a superior is more likely to stand on the superior's side, believing that whatever that superior does is just. The punishment is considered necessary for the company. A subordinate who perceives a positive leader-member exchange is also more likely to acknowledge the formal procedures used for punitive decisions and see that these procedures are executed by the superior. However, if a subordinate perceives a low (or negative) leader-member exchange, he or she does not consider the superior a trustworthy person and tends not to acknowledge that the punishment follows a due process. It is likely that the subordinate will consider the punishment too severe.

Unlike a superior, subordinates are in the position of being rewarded or punished. We used interpersonal liking to assess horizontal relationships between two colleagues. Here, liking the punished co-worker refers to a person's general attitude. Research has shown that the more a colleague likes a fellow employee, the more favorable are the evaluations of that employee (Anderson \& Shackleton, 1990; Cardy \& Dobbins, 1986; Wayne \& Liden, 1995; Wayne, Liden, Graf, \& Ferris, 1997). We expected to find that the degree of liking affects a person's justice perceptions of a punitive event. We anticipated that the better the liking 
relationship between a colleague and the punished employee, the less likely that the colleague would perceive the punishment as just. That is to say, the more a person likes his or her punished co-worker, the more he or she would empathize with that co-worker and see the punishment as unjust; if the punished co-worker was not liked, the punishment would be seen as just.

\section{Justice Perceptions Among Different Relational Types}

In considering effects that are a result of either vertical and horizontal relationships in a Chinese context, what does an organization member perceive when his or her co-worker is punished by a superior? To simplify the underlying relationships, we dichotomized each relationship (the superior-subordinate relationship and the subordinate-subordinate relationship) into high versus low. A high leader-member exchange/liking person refers to someone close to and with high trust in the focal person. A low leader-member exchange/liking person is someone distant from and with little trust in the focal person. Within this construct, we created the following four types of employees and derived justice perceptions in terms of each relational type:

Type 1: High leader-member exchange with the superior and low liking of the punished co-worker;

Type 2: High leader-member exchange with the superior and high liking of the punished co-worker;

Type 3: Low leader-member exchange with the superior and high liking of the punished co-worker; and

Type 4: Low leader-member exchange vith the superior and low liking of the punished co-worker.

\section{Justice Perceptions in Terms of Relational Types}

The Type 1 person tends to empathize with the superior's decisions more than with the punished co-worker. People close to a superior usually view the superior's actions as benevolent and reasonable. At the same time, those who are not close to the punished co-worker have a formal work relationship with the punished person. When the co-worker is punished, Type 1 people tend to attribute the blame to the co-worker, believing that he or she deserves the punishment and that the decision procedure follows a due process. For the Type 1 person, we predicted a high positive perception of distributive (a perception related to the fairness of punishment received) and procedural (a perception related to the fairness of the decision-making process) justice.

The Type 2 person maintains quality relationships with both the superior and the punished co-worker. Type 2 members face "social dilemmas," that is, situations in which social pressures come from two different sources. Type 2 people are good friends with the punished co-worker and tend to empathize with him or her. 
Because they are also close to the superior, they are also likely to agree that his or her actions are reasonable from the standpoint of management. A Type 2 member's favoring of one person may somehow hurt the relationship with the other party. One possible solution to disentangle the complexity in a Chinese society is to act according to the wu-lun principles. Drawing on the wu-lun principles, people often demand a higher expectation of someone with less power than one with greater power (Yang, 1993). If Type 2 people abide by such rules, all else being equal, we predicted that they would perceive moderate distributive and procedural justice.

The Type 3 person is not close to the superior but is close to the punished coworker. Of the four types, Type 3 people empathize most with the punished coworker and least with the superior. Although Type 3 people may abide by the wulun principles and turn away from their trusted co-worker, it is more probable that such rules will not dictate their perceptions in such cases. We argue here that the principle that vertical relationships supersede horizontal relationships may not be a general rule and tends to be situational. Rather than overriding a person's attitude when the issue is related to someone for whom the member has a strong affinity, this principle has an impact when no other salient social pressures are present or when the situation elicits no controversial demands. There are many cases in modern Chinese socicty, for instance, in which a person identifies with his or her spouse's behaviors while going against his or her parents. Today, a superior (as the Emperor in ancient days) may not elicit such a strong response as to cause abandonment of close friends or colleagues.

Consequently, we expected that Type 3 people would empathize with the punished co-worker, not with the superior. In addition, Type 3 people would be likely to have little chance to participate in the superior's decision processes and to have no knowledge of how the punishment decision was made. We expected that they would have low distributive and procedural justice perceptions.

The Type 4 person should be the most objective category because these people do not have close relationships with either the superior or the punished coworker. Relative to Type 1 and Type 2 people. Type 4 people tend to empathize little with the superior and have low justice perceptions. Relative to Type 3 people, Type 4 people tend to have high justice perceptions because they empathize less with the punished co-worker.

On the basis of the preceding arguments, using the concept of the leader-member exchange to assess subordinates' judgment of superiorsubordinate relationships and liking to assess horizontal relationships between two colleagues, we proposed the following hypothesis: There exist interaction effects on justice perceptions toward a co-worker's punitive event from (a) the leader-member exchange quality between a superior and a group member and (b) the liking between a group member and a punished co-worker.

In addition, although we expected to find that Type 3 individuals had the lowest justice perceptions, our arguments for predicting the specific differences among the four types are far from substantiated. This is especially the case 
because most Chinese indigenous concepts have not yet been tested empirically. To match the exploratory nature of the current literature, we did not specify our predictions on the differences among the four types. Consequently, we conducted post hoc tests in place of a priori tests in the analysis.

Finally, related literature suggests that an individual's view of the motive of justice (Lerner, 1977) may also affect justice perceptions (Ball et al., 1994). According to Lerner, justice is a basic need of human nature, and, consequently, organization members expect to see good behaviors rewarded and bad ones punished. Although the concept has been construed in a Western context, we expected to find that Chinese co-workers would also vary in their tendency to believe that the world is a just place. Hence, we needed to control such individual effects in our analysis. To test our hypothesis, we measured justice perceptions for the specific punitive events, leader-member exchange, liking, and the belief in a just world.

\section{Method}

\section{Procedure}

In Taiwan, members of businesses are usually of Chinese descent and are greatly affected by Confucian philosophy and beliefs. We used a convenience sampling technique to collect data: We first contacted the personnel or management office to get permission to do the survey. We asked whether the company had had a disciplinary incident within the past 6 months. We provided those companies that agreed to participate in the research with questionnaires and return envelopes. We asked the contact person in the company to write the name of the punished person and that of the supervisor in the designated blanks of the questionnaire. (We made sure that the punished person shared the same supervisor with the respondents.)

Although these procedures do not pose legal and privacy problems in Taiwan, they may create such issues in the United States. An alternative to this method would be to ask permission from the punished person and the supervisor. By doing so, however, one might have difficulty in acquiring enough participants for the survey or encounter potential sampling biases (e.g., we might have obtained highly inconsequential cases or ones of which everyone in the company was aware). We assured the respondents of confidentiality by saying that no scores would be disclosed to anyone other than the researchers. During the sampling process, however, most companies avcided telling the focal punished person and his or her supervisor about the survey.

\section{Participants}

We obtained a total of 104 usable resporises that contained 19 punitive cases in 15 companies. Cases included fist fighting, getting drunk during work hours, 
causing casualties at a construction site after disobeying safety rules, being extremely inefficient, and having bad work attitudes. The respondents were 40 women $(38.5 \%)$ and 64 men $(61.5 \%)$. Their work experience ranged from 1 to 33 years $(M=13$ years $)$, and their management experience ranged from 0 to 24 years $(M=6.6$ years $)$.

\section{Measures}

Justice perception. We adopted the Ball et al. (1994) justice perception questionnaire with a 5-point Likert-type scale to assess respondents' perceptions of punitive events. Because the original questionnaire was used to assess the punished person's justice perceptions, we changed the subject terms from "l" to "he" or "she." The Ball et al. factorial results showed four dimensions for procedural justice (constructiveness, subordinate control, privacy, and negative supervisor demeanor) and one dimension for distributive justice (harshness). We reversed the scores for harshness as the respondents' distributive justice scores, and we summed the scores for four subdimensions of procedural justice scores into the total scores.

Leader-member exchange. We asked the respondents to rate their perceived exchange relationships with their supervisors. We used Bauer and Green's (1996) 8-item quality of leader-member exchange questionnaire with a 7 point Likert-type scale. The questionnaire was originally designed by Scandura and Graen (1984). Examples of items are "I usually know where I stand with my manager"; "I usually know how satisfied my manager is with me"; "My manager recognizes my potential well"; and "I would characterize the relationship I have with my manager as extremely effective." Bauer and Green (1996) reported Cronbach alphas at different points in time as .92 and .94, respectively.

Belief in a just world. Rubin and Peplau (1973) used a 6-point Likert scale to develop the Belief in a Just World Questionnaire. The authors reported Cronbach alphas for two different samples as .80 and .81 , respectively.

We translated the three questionnaires into Mandarin, after which another bilingual colleague back-translated the Chinese version into English. The final Chinese version was based on extensive consultation with several Taiwanese professors in organizational behavior. In addition, after we finished our study, we came across a concurrent study by Gu (1999), who examined employees' organizational citizenship behavior in the Taiwanese information industry. Gu used Scandura and Graen's (1984) 7-item questionnaire with a back-translation technique. We compared Gu's version and our leader-member exchange questionnaire and found the two to contain similar expressions, providing additional external validity to our version. 
Liking. We designed two items to assess each respondent's liking of the punished person: (a) I like this person very much as a person and (b) I think the person would make a good friend (both items were in Mandarin Chinese). We asked for responses on a 7-point Likert-type scale.

\section{High Versus Low Dichotomy}

To create a $2 \times 2$ factorial design (Leader - Member Exchange $\times$ Liking), we dichotomized the respondents into high and low categories. We used the scores of a middle point (4) in the 7-point Likert-type scale. We then re-coded leader-member exchange and liking scores that were greater than four as high and scores of less than or equal to 4 as low. The resulting four cells were Type 1 (Leader-Member Exchange $>4$ and Liking $\leq 4$ ), 29 respondents; Type 2 (Leader-Member Exchange $>4$ and Liking > 4), 39 respondents; Type 3 (Leader-Member Exchange $\leq 4$ and Liking $>4$ ), 10 respondents; Type 4 (Leader-Member Exchange $\leq 4$ and Liking $\leq 4$ ), 26 respondents.

\section{Results}

Table 1 shows means, standard deviations, and correlation coefficients for the overall sample $(N=104)$. The findings incicated two significant relationships between these variables. Specifically, leader--member exchange was correlated with perceived procedural justice $(r=.38)$, and distributive justice was highly correlated with procedural justice $(r=.56)$; toth $p s<.001$. The measure of liking responses was not strongly correlated with any of the variables. These results suggest that the respondents who perceived themselves as close to a superior reported more procedural justice toward the punitive event. All the alpha coefficients for the scales were above the minimum acceptable value of .70 suggested by Nunnally (1978).

We performed a multivariate analysis of variance (MANOVA) to compare the

TABLE 1

Descriptive Statistics and Correlations $(N=104)$

\begin{tabular}{lllllll}
\hline Variable & $M$ & $S D$ & 1 & 2 & 3 & 4 \\
\hline 1. Leader-member exchange & 4.43 & 0.93 & .92 & & & \\
2. Liking & 4.29 & 1.33 & .07 & .95 & & \\
3. Distributive justice & 3.17 & 0.75 & .15 & -.11 &. $\mathbf{7 0}$ & \\
4. Procedural justice & 3.05 & 0.54 & $.38^{* * *}$ & .01 & $.56 * * *$ & $\mathbf{. 8 6}$ \\
\hline
\end{tabular}

Note. Cronbach alphas (in bold) are on the diagonal.

$* * * p<.001$. 

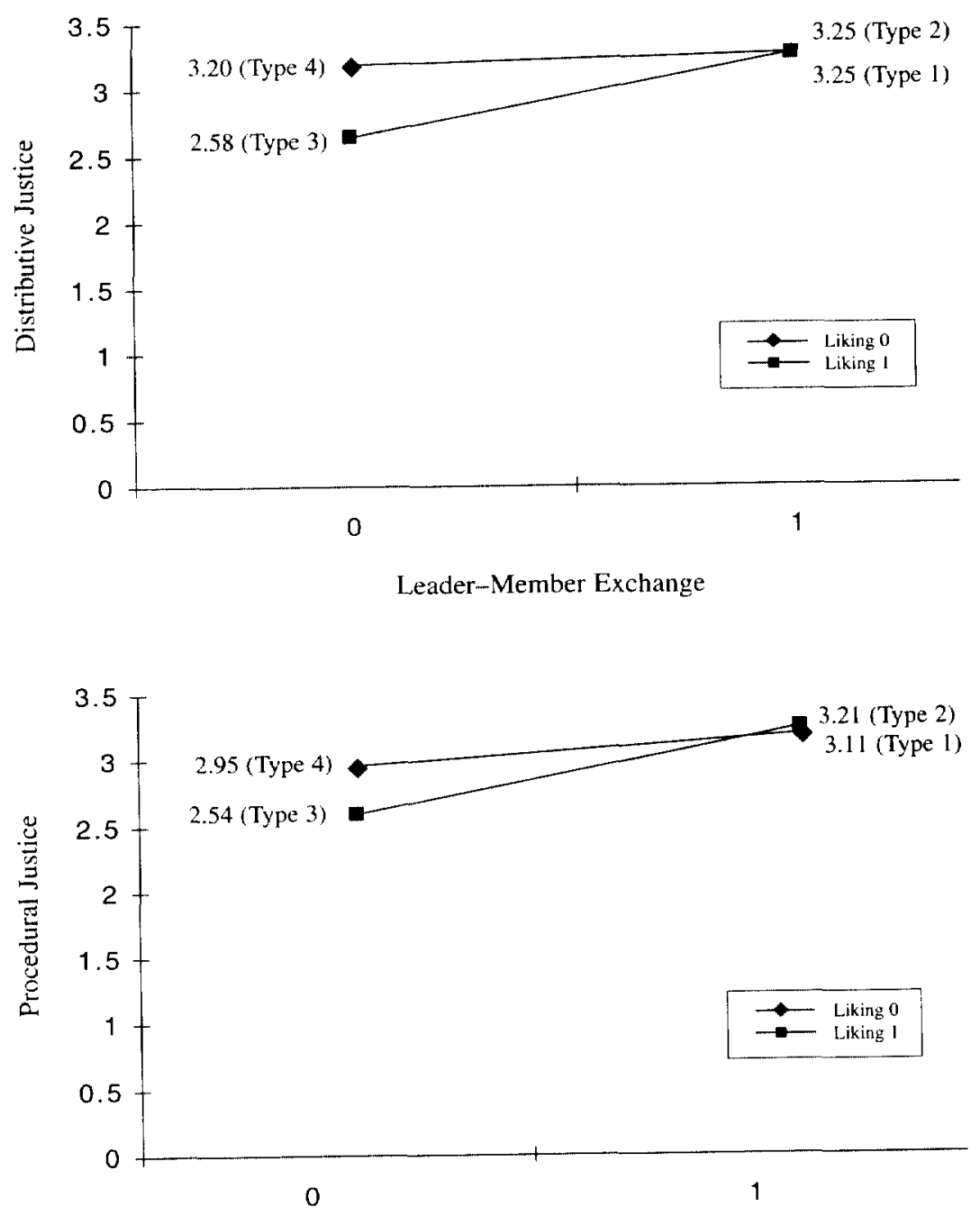

Leader-Member Exchange

FIGURE 1. Interaction effects between leader-member exchange and liking on distributive and procedural justice toward co-workers' punitive events. For leader-member exchange/liking, $1=$ high, $0=$ low. 
perceptions of distributive justice and of procedural justice simultaneously across two levels (high vs. low) of leader-member exchange and of liking and controlled the effects with belief in a just world. As Table: 1 shows, the scores of perceptions of distributive justice were highly correlated with those of procedural justice. The use of a MANOVA accounts for correlations within the dependent variables. Also, the MANOVA offered us means to examine the effect of two independent variables on two dependent variables without inflating the possibility of a Type I error and gave us the potential to gain a better picture of the data (Maxwell, 1992).

We used a MANOVA test on the interaction effect before conducting multiple comparisons of means. If a MANOVA shows significant differences, then each of the dependent variables can be examined to assess where the differences among types exist. Because of the exploratory nature of this study, we chose a relatively lenient $(p<.10)$ level of significance to test the hypothesis. The MANOVA revealed a significant multivariate Leader-Member Exchange $\times$ Liking interaction, Wilks's lambda $=.95, F(2,98 ;=2.56, p<.10$. Univariate $F$ tests also revealed a significant Leader-Member Exchange $\times$ Liking interaction on perceptions of distributive justice, $F(1,99)=2.91, p<.10$, and a significant Leader-Member Exchange $\times$ Liking interaction on perceptions of procedural

TABLE 2

Mean Scores for Distributive and Procedural Justice Toward Co-Worker's Punitive Events, by Leader-Member Exchange and Liking

\begin{tabular}{|c|c|c|c|c|c|c|}
\hline \multirow[b]{3}{*}{ Exchange/liking } & \multicolumn{4}{|c|}{ Liking } & & \\
\hline & \multicolumn{2}{|c|}{ Low } & \multicolumn{2}{|c|}{ High } & \multicolumn{2}{|c|}{ Total } \\
\hline & $\bar{M}$ & $S D$ & $M$ & $S D$ & $M$ & $S D$ \\
\hline \multicolumn{7}{|c|}{ Distributive justice } \\
\hline \multicolumn{7}{|c|}{ Leader-member exchange } \\
\hline High & $3.25_{\mathrm{a}}^{1}$ & 0.77 & $3.20_{\mathrm{a}}^{2}$ & 0.80 & 3.25 & 0.78 \\
\hline Low & $3.20_{\mathrm{ab}}^{\mathrm{a}}$ & 0.60 & $2.58_{b}^{3}$ & 0.72 & 3.03 & 0.68 \\
\hline Total & 3.23 & 0.69 & $3.11^{\mathrm{b}}$ & 0.82 & 3.17 & 0.75 \\
\hline
\end{tabular}

Procedural justice

Leader-member exchange

$\begin{array}{lllllll}\text { High } & 3.11_{\mathrm{a}}^{1} & 0.59 & 3.21_{\mathrm{a}}^{2} & 0.49 & 3.17 & 0.53 \\ \text { Low } & 2.95_{\mathrm{ab}}^{4} & 0.43 & 2.54_{\mathrm{b}}^{3} & 0.59 & 2.84 & 0.51 \\ \text { Total } & 3.03 & 0.52 & 3.08 & 0.57 & 3.05 & 0.54\end{array}$

Note. $N=104$. Superscripts indicate type number. Subscripts indicate results of Scheffé post hoc comparison of means. Means with no subscripts in common differ significantly, as indicated by a least significant difference test for multiple comparisons between means.

For distributive justice, $p<.10$; for procedural justice, $p<.05$. 
justice, $F(1,99)=4.77, p<.05$, thus supporting our proposed hypothesis. A plot of the mean scores for each type is shown in Figure 1.

To identify the source of the interaction effects, we then conducted a Scheffé post hoc comparison of means. Results of the Scheffé tests (Table 2) showed that respondents with high liking relationships with the punished and low exchange relationships with the superior (Type 3 respondents) perceived punitive events as significantly lower in distributive justice than did Type 1 and Type 2 respondents $(p s<.10)$. Furthermore, results of the Scheffé tests revealed that Type 3 respondents also perceived punitive events as lower in procedural justice than did Type 1 and Type 2 respondents ( $p s<.05$ ).

Finally, a higher belief in a just world, the covariate, led to more positive perceptions of distributive justice, $F(1,99)=4.36, p<.05$; however, a higher belief in a just world did not lead to more positive perceptions of procedural justice, $F(1,99)=.13, p>.10$.

\section{Discussion}

Recent studies have shown that managers acknowledge the existence of social effects resulting from discipline (Atwater et al., 2001; Butterfield, Trevino, \& Ball, 1996). Atwater et al. (2001) found significant differences between the perceptions of third-party observers and those of managers and the recipients of the punishment. Yet, the underlying cause for such potential social effects has been largely unexplored. To explore these effects, we adopted a relational perspective and studied organization members' justice perceptions toward a coworker's punitive event in terms of vertical and horizontal relationships simultaneously. This research adds to the literature on organizational justice in general and specifically to literature on Chinese organizational behavior.

This study provides evidence for a relational model of social justice in the context of Chinese culture. In Figure 1, we see that those with the lowest justice perceptions were the ones with high liking scores and low leader-member exchange scores. Hence, as expected from our hypothesis, the magnitude and type of relationship with superior and colleague jointly determined a person's justice evaluations.

We may also use Lind and Tyler's (1988) group-value model to interpret our results. Group members construct their identities on the basis of the groups to which they belong, what they think of the groups, and how their groups function. They form justice perceptions through the influences of those around them (cf. Lind et al., 1998). Our data provide evidence that the respondents' justice perceptions were strongly correlated with their relationships with superiors. Members value their group's decisions, and they generally are willing to act accordingly. This interpretation parallels the Atwater et al. (2001) findings that, compared with the punished co-worker, the third-party observers reported more vicarious learning from the discipline event. 
In addition, our study supplemented a group-value model by adding a differential effect for group members in terms of justice perceptions. That is to say, viewing the group as a whole to be the source of a member's identity oversimplifies the phenomenon. Group members hold multiple relationships with superiors and colleagues. The overall, interrelated relationships determine their final justice evaluations.

This study does have several limitations. First, we used leader-member exchange and liking as approximations of vertical and horizontal relationships. There may exist multiple dimensions of vertical relationships and horizontal relationships. Leader-member exchange and liking represent only limited assessments of a complicated social phenomenon. We must be very careful in interpreting the data.

Furthermore, there is a potential social desirability bias for the liking scale. We used two positive items to measure liking that might have encouraged our respondents to respond favorably toward the target co-worker. The results for the privacy dimension of procedural justice in our study might contain biases. If perfect privacy did exist, it would have been imfossible for us to conduct research, for in order to respond to our questionnaires: the organization members had to have at least minimum knowledge about the punitive events. Those who knew nothing about the events had been excluded, so our sample contained only a partial list of all potential respondents.

Finally, a number of companies declined our request and did not participate in our survey. We would have no way of knowing how the particular companies who agreed to participate might be similar to or different from other companies in Taiwan, so we cannot generalize our study results beyond the particular convenience sample.

By performing this study, we hoped to draw attention to a non-Western examination of issues of organizational justice. Our data provide a preliminary answer to our proposed question. We believe that comparative studies on organizational justice will definitely be a promising direction $\mathrm{a}$ or future research. For instance, in a recent article, Mueller, Iverson, and Jo (1999) reported the societal and cultural differences of middle school and high school teachers' distributive justice evaluations. It is likely that indigenous ethical principles in each culture may be used as justifications or excuses in resolving social and organizational conflicts.

When these ethical or ideological accounts will be used and when they will not be used is a starting point for a more general framework of organizational justice (cf. Schminke, Ambrose, \& Noel, 1997). We found evidence within an indigenous postulation of organizational justice in Taiwan, and we will surely see promising research outcomes in relation to justice in communist China (cf. Meindl, Hunt, \& Cheng, 1994). Nevertheless, we wonder, can corporate employees in more traditional societies such as China reconcile social dilemmas simply by abiding by an ancient philosophy, or should they pursue other means to achieve justice? These questions remain unanswered and require further exploration in future studies. 
Finally, people's justice perceptions may also be affected by their beliefs about justice in the world around them. Lerner (1977) has successfully found evidence for a just world motive theory in North American culture (Tanaka, 1999), but this theory has not been tested widely in Eastern cultures. Our MANOVA results did show a significant effect of belief in a just world on respondents' distributive justice perceptions. Thus, it is likely that Taiwanese employees' justice perceptions regarding the severity of co-workers' punishment are determined more in terms of their just world motives and beliefs than in relational terms. The existence of justice motives and their effects on organizational behavior is a promising subject for future studies across cultures.

\section{REFERENCES}

Anderson, N., \& Shackleton, V. (1990). Decision making in the graduate selection interview: A field study. Journal of Occupational Psychology, 63, 63-76.

Arvey, R. D., \& Ivancevich, J. M. (1980). Punishment in organizations: A review, propositions, and research suggestions. Academy of Management Review, 5, 123-132.

Atwater, L. E., Waldman, D. A., Carey, J. A., \& Cartier, P. (2001). Recipient and observer reactions to discipline: Are managers experiencing wishful thinking? Journal of Organizational Behavior, 22, 249--270.

Ball, G. A., Trevino, L. K., \& Sims. H. P. (1994). Just and unjust punishment: Influences on subordinate performance and citizenship. Academy of Management Journal, 37, 299-322.

Batson, D. C. (1991). The altruism question: Toward a social-psychological answer. Hillsdale, NJ: Erlbaum.

Bauer, T. N., \& Green, S. G. (1996). Development of leader-member exchange: A longitudinal test. Academy of Management Journal, 39, 1538-1567.

Blader, S. L., \& Tyler, T. R. (2000, August). What constitutes fairness in work settings? A four-component model of procedural justice. Paper presented at the annual meeting of the Academy of Management, Toronto, Canada.

Butterfield, K. D., Trevino, L. K., \& Ball, G. A. (1996). Punishment from the manager's perspective: A grounded investigation and inductive model. Academy of Management Journal, 39, 1479-1512.

Cardy, R. L., \& Dobbins, G. H. (1986). Affect and appraisal accuracy: Liking as an integral dimension in evaluating performance. Journal of Applied Psychology, 71, 672-678.

Dailey, R., \& Kirk, D. (1992). Distributive and procedural justice as antecedents of job satisfaction and intent to turnover. Human Relations, 45, 305-317.

Darley, J. M., \& Fazio, H. (1980). Expectancy confirmation process arising in the social interaction sequence. American Psychologist, 35, 867-881.

Davidson, M., \& Friedman, R. A. (1998). When excuses don't work: The persistent injustice effect among Black managers. Administrative Science Quarterly, 43, 154-183.

Farh, J., Earley, P. C., \& Lin, S. (1997). Impetus for action: A cultural analysis of justice and organizational citizenship behavior in Chinese society. Administrative Science Quarterly, 42, 421-444.

Folger, R., \& Cropanzano, R. (1998). Organizational justice and human resource management. Thousand Oaks, CA: Sage.

Graen, G. B., \& Scandura, T. A. (1987). Toward a psychology of dyadic organizing. In B. M. Staw \& L. L. Cummings (Eds.), Research in organizational behavior (pp. 175-208). Greenwich, CT: JAI Press. 
Greenberg, J. (1996). The quest for justice on the job. Thousand Oaks, CA: Sage.

$\mathrm{Gu}, \mathrm{C}$. (1999). A study on organizational citizenship behavior of $R \& D$ personnel in information industries. Unpublished master's thesis, National Defense University, Taiwan. (in Chinese)

Hofstede, G. (1980). Cultural consequences. Beverly Hills, CA: Sage.

Hwang, K. K. (2000). Chinese relationalism: Theoretical construction and methodological considerations. Journal for the Theory of Social Behavior, 30, 155-178.

Konovsky, M. A. (2000). Understanding procedural justice and its impact on business organizations. Journal of Management, 26, 489--511.

Konovsky, M. A., \& Cropanzano, R. (1991). Perceived fairness of employee drug testing as a predictor of employee attitudes and job per ormance. Journal of Applied Psychology, 76, 698-707.

Lerner, M. J. (1977). The justice motive: Some hypotheses as to its origins and forms. Journal of Personality, 45, 1-52.

Leung, K., \& Bond, M. H. (1984). The impact of cultural collectivism on reward allocation. Journal of Personality and Social Psycholegy, 47, 793-804.

Lind, E. A., \& Earley, P. C. (1992). Procedural justice and culture. International Journal of Psychology, 27, 227-242.

Lind, E. A., Kray, L., \& Thompson, L. (1998). The social construction of injustice: Fairness judgments in response to own and others' unfair treatment by authorities. Organizational Behavior and Human Decision Processes, 75, 1-21.

Lind, E. A., \& Tyler, T. R. (1988). The social psychology of procedural justice. New York: Plenum.

Luthans, F., \& Kreitner, R. (1985). Organizational behavior modification and beyond. Glenview, IL: Scott, Foresman.

Maxwell, S. E. (1992). Recent developments in MANOVA applications. In B. Thompson (Ed.), Advances in social science methodology (Vol. 2, pp. 137-168). Greenwich, CT: JAI Press.

McFarlin, D. B., \& Sweeney, P. D. (1992). Distributive and procedural justice as predictors of satisfaction with personal and organizational outcomes. Academy of Management Journal, 35, 626-637.

Meindl, J. R., Hunt, R. G., \& Cheng, Y. K. (1994). Justice on the road to change in the People's Republic of China. Social Justice Research, 7, 197-224.

Moorman, R. H. (1991). Relationship between organizational justice and organizational citizenship behavior: Do fairness perceptions inlluence employee citizenship? Journal of Applied Psychology, 76, 845-855.

Moorman, R. H., Blakely, G. L., \& Niehoff, B. P. (1998). Does perceived organizational support mediate the relationship between procedural justice and organizational citizenship behavior? Academy of Management Journal, 41, 351-357.

Mueller, C. W., Iverson, R. D., \& Jo, D. (1999). Dis ributive justice evaluations in two cultural contexts: A comparison of U.S. and South Korean teachers. Human Relations, 52, 869-893.

Nunnally, J. C. (1978). Psychometric theory. New York: McGraw-Hill.

Rubin, Z., \& Peplau, A. (1973). Belief in a just world and reactions to another's lot: A study of participants in the national draft lottery. Journal of Social Issues, 29, 73-93.

Scandura, T. A., \& Graen, G. B. (1984). Moderating effects of initial leader-member exchange status on the effects of a leadership intervention. Journal of Applied Psychology, $69,428-436$.

Schminke, M., Ambrose, M. L., \& Noel, T. W. (1597). The effect of ethical frameworks on perceptions of organizational justice. Academy of Management Journal, 40 , $1190-1207$. 
Tanaka, K. (1999). Judgments of fairness by just world believers. The Journal of Social Psychology, 139, 631-638.

Thibaut, L. W., \& Walker, L. (1975). Procedural justice: A psychological perspective. Hillsdale, NJ: Erlbaum.

Trevino, L. K. (1992). The social effects of punishments in organizations: A justice perspective. Academy of Management Review, 17, 647-676.

Tyler, T. R., \& Lind, E. A. (1992). A relational model of authority in groups. Advances in Experimental Social Psychology, 25, 119-191.

Wayne, S. J., \& Liden, R. C. (1995). Effects of impression management on performance ratings: A 1. Academy of Management Journal, 38, 232.

Wayne, S. J., Liden, R. C., Graf, I. K., \& Ferris, G. R. (1997). The role of upward influence tactics in human resource decisions. Personnel Psychology, 50, 979-1006.

Yang, K. (1993). Chinese social orientation: An integrative analysis. In L. Y. Cheng, F. M. C. Cheung, \& C.-N. Chen (Eds.), Psychotherapy for the Chinese: Selected papers from the First International Conference (pp. 19-56). Hong Kong: Chinese University of Hong Kong.

Yates, J. F., \& Lee, J. (1996). Chinese decision making. In M. H. Bond (Ed.), The handbook of Chinese psychology (pp. 338-351). Hong Kong: Oxford University Press.

Yukl, G. (2000). Leadership in organizations (4th ed.). Englewood Cliffs, NJ: Prentice-Hall.

Received November 20, 2000

Accepted November 7, 2001 


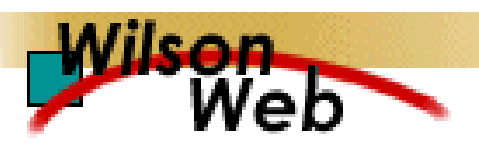

\section{COPYRIGHT INFORMATION}

TITLE: Taiwanese Employees' Justice Perceptions of Co-Workers' Punitive Events

SOURCE: The Journal of Social Psychology 143 no1 F 2003

PAGE(S): 27-42

WN: 0303202149002

The magazine publisher is the copyright holder of this article and it is reproduced with permission. Further reproduction of this article in violation of the copyright is prohibited. To contact the publisher: http://www.heldref.org/

Copyright 1982-2003 The H.W. Wilson Company. All rights reserved. 